\title{
Continued Growth of Escherichia coli after Stopping Medium Addition to a $\mathrm{K}^{+}$-limited Chemostat Culture
}

\author{
By MARCEL M. MULDER, † HANNEKE M. L. VAN DER GULDEN, \\ PIETER W. POSTMA AND KAREL VAN DAM* \\ Laboratory of Biochemistry, University of Amsterdam, PO Box 20151, 1000 HD Amsterdam, \\ The Netherlands
}

(Received 29 April 1987; revised 3 November 1987)

\begin{abstract}
The steady-state bacterial dry wt of Escherichia coli, growing under $\mathrm{K}^{+}$-limited conditions in the chemostat, was inversely dependent on the growth rate. This phenomenon was more carefully investigated in medium-flow stop experiments. Growth did not stop immediately but continued for a time, initially at the same rate as before. The dry wt increased to a value corresponding to a steady-state growth rate near zero, independent of the initial specific growth rate. This was observed in both the wild-type strain and a mutant that lacked the high-affinity $\mathrm{K}^{+}$uptake system. The wild-type strain maintained a low extracellular $\mathrm{K}^{+}$concentration both in the chemostat under steady-state conditions and after stopping the medium flow. The mutant, on the other hand, maintained a much higher extracellular $\mathrm{K}^{+}$concentration in the steady state, which decreased to much lower values after stopping the medium flow. From the increase in bacterial dry wt and the low external $\mathrm{K}^{+}$concentration after stopping the medium flow it is concluded that the intracellular $\mathrm{K}^{+}$is redistributed among the cells, including new cells. The growth yield on $\mathrm{K}^{+}$was highest in the stationary growth phase of a batch culture and all steadystate cultures converged ultimately to this yield value after the medium flow had been stopped. It is proposed that the growth rate of $E$. coli under $\mathrm{K}^{+}$-limited conditions is determined by the intracellular $\mathrm{K}^{+}$concentration.
\end{abstract}

\section{INTRODUCTION}

In a previous paper we proposed that a futile cycle of $\mathrm{K}^{+}$existed in Escherichia coli (Mulder $e t$ al., 1986). Differences in ATP production rate were shown between E. coli FRAG 1, a strain having the proposed futile cycle, and $E$. coli FRAG 5, a mutant lacking the high-affinity $\mathrm{K}^{+}$ uptake system and thus lacking futile cycling of $\mathrm{K}^{+}$. From batch culture experiments with FRAG 1 and FRAG 5 on the same minimal salts medium as was used in chemostat culture, it was observed that after reaching the stationary phase the yield on $\mathrm{K}^{+}$was higher than was observed in the chemostat at any steady-state growth rate. It was of interest therefore to examine the two $E$. coli strains under different conditions. We investigated the growth behaviour of FRAG 1 under $\mathrm{K}^{+}$-limited conditions after interrupting the medium flow, thus changing from a steady-state culture to a culture ultimately in the stationary phase. The results were compared with those from FRAG 5 to investigate what effect the difference in ATP turnover would have on this transition.

$\mathrm{K}^{+}$-limited cultures of micro-organisms differ from other limited cultures, such as glucoselimited or ammonia-limited cultures, in that the limiting substrate is not being metabolized.

There are several theories as to the function of intracellular $\mathrm{K}^{+}$(Tempest et al., 1966; Epstein \& Davies, 1970; Walderhaug et al., 1988): (i) it activates a number of cellular enzymes (for a review see Walderhaug et al., 1988); (ii) it plays a role in the maintenance of the osmotic pressure

+ Present address: Institute for Livestock Feeding and Nutrition Research, PO Box 160, 8200 Lelystad, The Netherlands. 
(Durgaryan \& Martirosov, 1978; Epstein \& Laimins, 1980; Meury \& Kepes, 1981; Meury et al., 1985 ; Epstein, 1986); and (iii) it plays an important role in the regulation of the intracellular $\mathrm{pH}$ of bacteria (Booth, 1985).

In $\mathrm{K}^{+}$-limited steady-state chemostat cultures of $E$. coli, the intracellular $\mathrm{K}^{+}$concentration increases with increasing growth rate (Tempest et al., 1966). At a low growth rate $\left(\mu=0 \cdot 1 \mathrm{~h}^{-1}\right)$ the intracellular concentration was about $100 \mathrm{mM}$ and increased to $200 \mathrm{~mm}$ at higher growth rates (Hueting et al., 1979). This increase in intracellular $\mathrm{K}^{+}$concentration correlates with a decrease in bacterial dry wt when the growth rate is increased (Mulder et al., 1986). Steady-state cultures of $E$. coli show a strong dependence of the bacterial dry wt on the growth rate under $\mathrm{K}^{+}$ limited conditions (Mulder et al., 1986). A similar decrease in yield with increasing growth rate was observed under $\mathrm{Mg}^{2+}$-limited (Tempest et al., 1965) and phosphate-limited conditions (Tempest et al., 1966) in steady-state cultures of Aerobacter aerogenes. Under ammonia-limited conditions, a variation in yield was also observed (Herbert, 1961); however, the change in biomass is fully accounted for by the formation of large amounts of glycogen at low growth rates, whereas at higher growth rates the amount of glycogen is reduced to a very low level. Under glucose-limited conditions a constant bacterial dry wt was reported at all growth rates (Herbert et al., 1961; M. M. Mulder, unpublished results).

In this paper we studied the phenomenon of strongly varying dry wt with growth rate more carefully in chemostats. During such experiments the medium flow was interrupted and from that time on growth parameters and $\mathrm{K}^{+}$concentrations were recorded.

\section{METHODS}

Organisms. Two strains of $E$. coli were used in these experiments: E. coli FRAG 1 (thi rha lac $Z$ gal) and E. coli FRAG 5 (thi rha lac Z gal kdpABC5) (Epstein \& Davies, 1970) (kindly donated by W. Epstein, University of Chicago, USA).

Experimental conditions. Experiments were done in a 1 litre fermenter (500 series, LH Engineering) with a magnetic stirring device. The culture volume in the steady state was approximately $400 \mathrm{ml}$. A simple salts medium was used as specified by Evans et al. (1970) with $1 \mathrm{mM}-\mathrm{K}^{+}$as the limiting factor; $166 \mathrm{mM}$-glucose was added as sole carbon and energy source. Thiamin hydrochloride (Sigma) $(10 \mathrm{mg}$ per litre of medium) was added also. Media were filter-sterilized using Millipore filters $(0.22 \mu \mathrm{m})$. The $\mathrm{pH}$ value of the cultures was monitored constantly and maintained at $6.9 \pm 0.1$ by automatic addition of sterile $4 \mathrm{M}-\mathrm{NaOH}$. The temperature was set at $35 \pm 1{ }^{\circ} \mathrm{C}$. The cultures were stirred at 1100 r.p.m. and were aerated by flushing air $\left(20-301 \mathrm{~h}^{-1}\right)$ through the culture. Foaming was controlled with a foam sensor and by addition of silicone antifoaming agent (BDH). In the steady state, samples were taken for measurements of bacterial $\mathrm{dry}$ wt, for protein determination, viable cell counting, particle counting by Coulter counter, determination of extracellular fluid composition, and intracellular and extracellular $\mathrm{K}^{+}$measurements. When the steady state had been established, further addition of medium was stopped. Every $15 \mathrm{~min}$, samples were taken for a period of up to $5 \mathrm{~h} . \mathrm{O}_{2}$ consumption, $\mathrm{CO}_{2}$ production and $\mathrm{pH}$ were also monitored. Products and glucose were separated by HPLC using a BioRad HPX 87 column and detected with a refractometer (Knauer). Perchloric acid $(0.1 \mathrm{ml}, 15 \% \mathrm{w} / \mathrm{v})$ was added to $0.5 \mathrm{ml}$ sample in order to deproteinate the samples. After $5 \mathrm{~min}$, samples were centrifuged and the supernatant was used for measurements. After applying a deproteinated sample to the column, the column was eluted with sulphuric acid $(0.005 \mathrm{M})$ at room temperature at a flow rate of $30 \mathrm{ml} \mathrm{h}^{-1}$. Bacterial dry wt was measured according to the method of Herbert et al. (1965). Protein was determined using the method of Lowry, modified according to Peterson (1977). Bovine serum albumin (Sigma) was used as a standard. Viable cell counts were made by diluting samples $10^{8}$-fold in sterile $0.9 \%(\mathrm{w} / \mathrm{v}) \mathrm{NaCl}$ and plating $100 \mu \mathrm{l}$ on nutrient agar plates (Gibco). For Coulter counter measurements, $25 \mu \mathrm{l}$ cells were fixed in $475 \mu \mathrm{l}$ formaldehyde $(3 \%, \mathrm{w} / \mathrm{v}) . \mathrm{O}_{2}$ consumption was measured with a Servomex $580 \mathrm{~A}$ oxygen analyser and $\mathrm{CO}_{2}$ production was measured with a Servomex PA 404 analyser.

$K^{+}$determination. A sample of culture fluid $(1 \mathrm{ml})$ was placed on top of $0.5 \mathrm{ml}$ silicone oil [3:1 mixture of AR200/AR20 (Wacker Chemie)] in an Eppendorf tube. This was centrifuged for $30 \mathrm{~s}$ in order to separate cells and external fluid. The supernatant was used for measurement of external $\mathrm{K}^{+}$concentrations. The pellet was resuspended in $500 \mu \mathrm{l}$ of water and $100 \mu \mathrm{l}$ perchloric acid $(7.5 \%$, w/v) was then added. Potassium was determined with a Hitachi atomic absorption spectrophotometer, model 180-80.

\section{RESULTS}

The dry wt of $E$. coli cells grown under aerobic conditions in steady-state $\mathrm{K}^{+}$-limited cultures strongly depended on the growth rate (Fig. 1). The bacterial dry wt decreased from $3.5 \mathrm{~g} \mathrm{l}^{-1}$ at a 


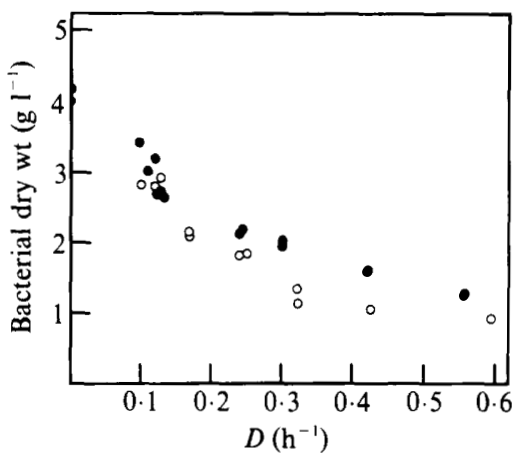

Fig. 1. Dependence of the steady-state dry wt of $E$. coli on the growth rate in $\mathrm{K}^{+}$-limited chemostat cultures. FRAG $1 ; 0$, FRAG 5 . The experimental points at $D=0$ are derived from a batch culture grown until a stationary state was reached.

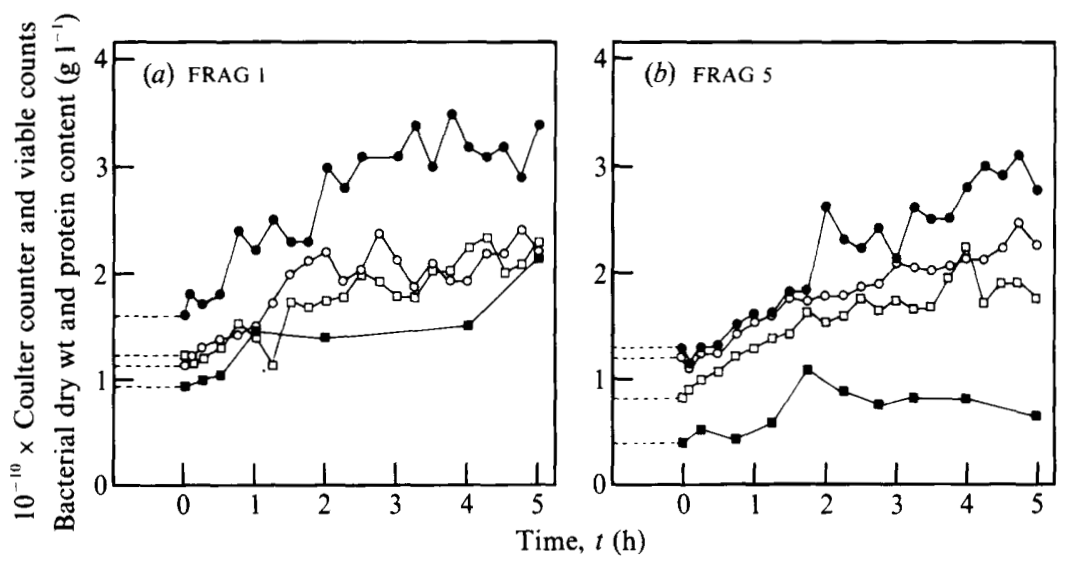

Fig. 2. Change in parameters related to cell number after interrupting the medium flow for $E$. coli FRAG $1(a)$ and FRAG $5(b)$. The specific growth rate before interrupting the flow of medium was $0.42 \mathrm{~h}^{-1}$. , Bacterial dry wt; $O$, protein content; $\square$, viable cell count; $\square$, numbers obtained with the Coulter counter.

growth rate of $0 \cdot 1 \mathrm{~h}^{-1}$ to $1.0 \mathrm{~g}^{-1}$ at a growth rate of $0.6 \mathrm{~h}^{-1}$. The yield in the stationary phase of a batch culture might be equivalent to a dilution rate of zero. This decrease in bacterial dry wt with increasing growth rate was more carefully studied in medium-flow stop experiments. A chemostat was inoculated with $E$. coli FRAG 1 at a growth rate of $0.42 \mathrm{~h}^{-1}$. After the steady state had been reached, the medium flow was interrupted and samples were taken every $15 \mathrm{~min}$. The bacterial dry wt, constant in the steady state $(t<0)$, increased from $1.6 \mathrm{~g} \mathrm{l}^{-1}$ at $t=0$ to $3.3 \mathrm{~g} \mathrm{l}^{-1}$ at $t=300 \mathrm{~min}$ (Fig. $2 a$ ). We also measured the protein content of the cells, the number of viable cells and the number of particles counted in a Coulter counter (Fig. $2 a$ ). All the abovementioned parameters showed a similar increase to the bacterial dry wt.

We showed previously that $E$. coli FRAG 5 , a mutant lacking the high-affinity $\mathrm{K}^{+}$uptake system, behaved differently from the wild-type FRAG 1 when grown in the chemostat under $\mathrm{K}^{+}$-limited conditions (Mulder et al., 1986). The ATP production rate of the wild-type exceeded that of the mutant strain at all growth rates (Mulder et al., 1986). Also, the wild-type maintained the extracellular $\mathrm{K}^{+}$concentration at a much lower value $(<0.6 \mu \mathrm{M})$ than did FRAG 5 (about $50 \mu \mathrm{M})$ at all growth rates. Therefore, we also did a medium-flow stop experiment with the mutant strain FRAG 5 (Fig. $2 b$ ). No gross differences were observed between the two strains.

We determined the extracellular $\mathrm{K}^{+}$concentrations in the culture, interrupted at a steadystate growth rate of $0.42 \mathrm{~h}^{-1}$ for both FRAG 1 and FRAG 5 (Fig. 3). FRAG 1 maintained a low 


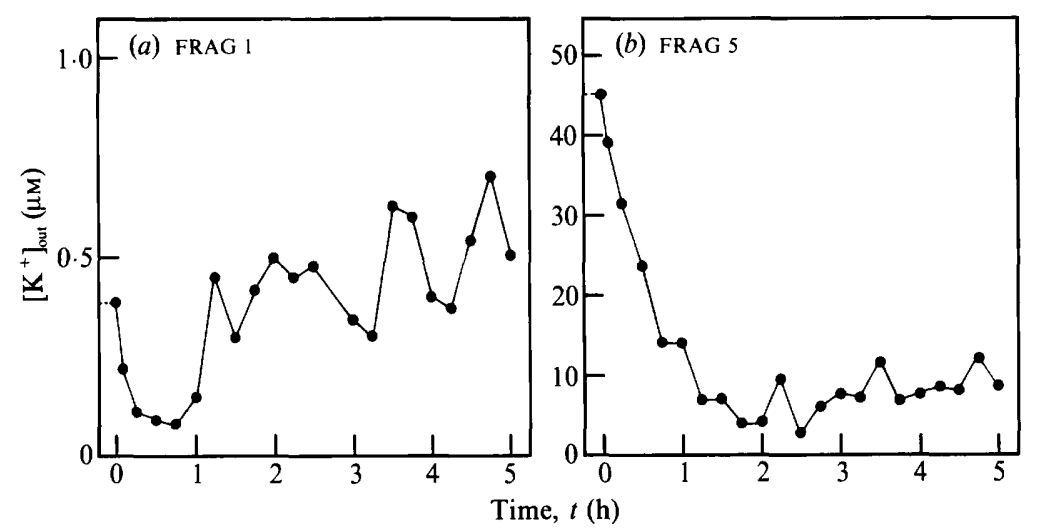

Fig. 3. Change in extracellular $\mathrm{K}^{+}$concentration after stopping the medium flow for $E$. coli FRAG 1 (a) and FRAG $5(b)$.
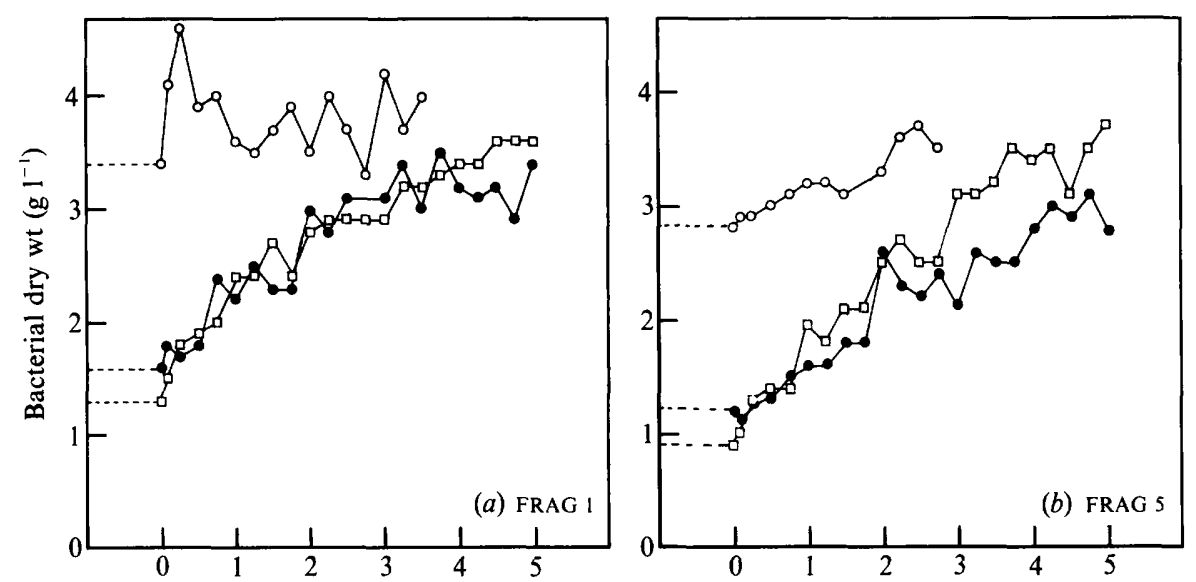

Time, $t(\mathrm{~h})$

Fig. 4. Change in bacterial dry wt after stopping the medium flow for $E$. coli FRAG $1(a)$ and FRAG 5 (b). $\square$, Steady state at $0.56 \mathrm{~h}^{-1} ; O$, steady state at $0.42 \mathrm{~h}^{-1} ; O$, steady state at $0.10 \mathrm{~h}^{-1}$.

$\mathrm{K}^{+}$concentration during the whole experiment. From $t=0$ to $t=45 \mathrm{~min}$, the extracellular $\mathrm{K}^{+}$ concentration seemed to decrease somewhat further but later it stabilized again at a value similar to that found in the steady state. The results for FRAG 5 were different. The extracellular $\mathrm{K}^{+}$concentration was relatively high in the steady state (about $50 \mu \mathrm{M}$ ), but this concentration decreased to a new level of $7-10 \mu \mathrm{M}$ during the rest of the experiment after interruption of the medium flow.

It appears that the amount of bacteria after the medium flow had been stopped for several hours increased to a value that could be calculated by extrapolation to a growth rate of near zero in the graph describing the relationship between dry wt and steady-state growth rate. If this were really the case, one should expect an even larger increase in all the measured parameters if the experiment were to be started from a higher steady-state growth rate. On the other hand, if such an experiment were to be started with a culture with a lower steady-state growth rate, one would expect only a small increase in all these parameters. In Fig. 4(a) the results of such experiments are plotted for FRAG 1 . As a representative biomass parameter, only the bacterial dry wt is given, but the other parameters gave a similar pattern. As expected, the culture starting with a 


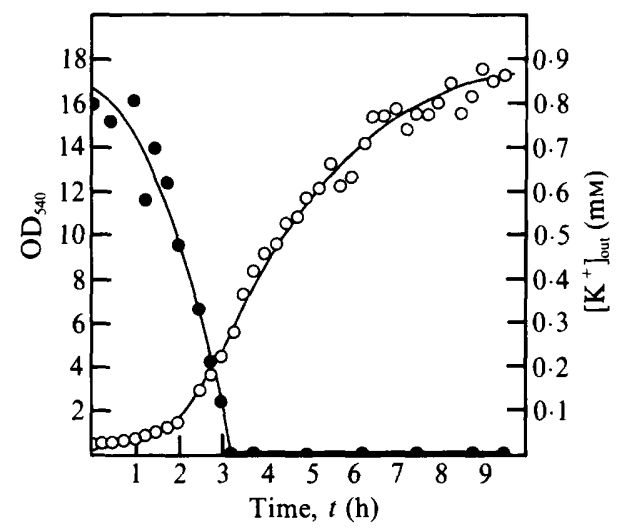

Fig. 5. Growth of $E$. coli FRAG 1 in batch culture, measured as an increase in optical density $(540 \mathrm{~nm})$ against time $(\mathrm{O})$. Extracellular $\mathrm{K}^{+}$concentrations were measured at the indicated time points $(O)$.

higher steady-state growth rate $\left(\mu=0.56 \mathrm{~h}^{-1}\right)$ showed a larger increase than the culture starting from a growth rate of $0.42 \mathrm{~h}^{-1}$ (Fig. $4 a$ ); that started from a steady-state growth rate of $0.1 \mathrm{~h}^{-1}$ showed only a very small increase in bacterial dry wt. In this respect the mutant strain and the parent strain behaved similarly (Fig. 4). All steady-state cultures ultimately converged to a similar bacterial dry wt independent of the starting conditions for each of the two strains.

Apart from new cells, $\mathrm{CO}_{2}$, acetic acid and pyruvate (the latter in small amounts) were also formed after stopping the medium flow. Measuring the change in glucose concentration with time in the extracellular fluid showed that glucose was initially taken up at the same rate $\left(12 \mathrm{mmol} \mathrm{g}^{-1} \mathrm{~h}^{-1}\right.$ for the culture with a growth rate of $\left.0.42 \mathrm{~h}^{-1}\right)$ as in the steady state before stopping the medium flow.

All experiments described so far were done starting from a chemostat culture in the steady state. As maximal growth rates are achieved during unlimited exponential growth, FRAG 1 and FRAG 5 were also grown in batch culture in the same minimal salts medium with $166 \mathrm{~mm}$ glucose as the carbon source and $1 \mathrm{mM}-\mathrm{KCl}$. Acidification of the medium was prevented by addition of $\mathrm{NaOH}$. The bacterial dry wt of these cultures measured after the stationary phase had been reached (after $24 \mathrm{~h}$ ) was $4.0 \mathrm{~g}^{-1}$ for FRAG 1 and $4.2 \mathrm{gl}^{-1}$ for FRAG 5. The stationary phase may be considered to be a condition with $D=0$ in the chemostat. The results are plotted in Fig. 1 at a dilution rate of zero $(D=0)$.

FRAG 1 was grown again on the same minimal medium in batch culture and growth was monitored. During growth, samples were taken every $15 \mathrm{~min}$ for external $\mathrm{K}^{+}$measurements. After a lag phase, the cells started to grow at their maximal growth rate $\left(\mu=0.7 \mathrm{~h}^{-1}\right)$. At a certain time $(t=195 \mathrm{~min}), \mathrm{K}^{+}$became limiting. As can be seen in Fig. 5 , the culture continued to grow at the same rate for some time, while the extracellular $\mathrm{K}^{+}$concentration was very low. The same observations were made in the medium-flow stop experiments described above, where it was seen that glucose uptake rate and product formation rate did not change after interrupting the medium flow.

In both the steady-state and the batch-culture experiments, glucose must be present. When the cultures ran out of glucose, the $\mathrm{pH}$ of the medium increased to 8.5 and higher. Together with this increase in $\mathrm{pH}$, the extracellular $\mathrm{K}^{+}$concentration increased (not shown). At the same time, $\mathrm{O}_{2}$ consumption and $\mathrm{CO}_{2}$ production decreased very rapidly. During the medium-flow stop experiment, starting with a dilution rate of $0.42 \mathrm{~h}^{-1}$ with FRAG 1 , the $\mathrm{O}_{2}$ consumption rate calculated from the effluent gas was about $5.4 \mathrm{mmol} \mathrm{g}^{-1} \mathrm{~h}^{-1}$. After glucose depletion, the $\mathrm{O}_{2}$ consumption rate decreased to $1.8 \mathrm{mmol} \mathrm{g}^{-1} \mathrm{~h}^{-1}$. When glucose was added again to the glucosedepleted culture, the whole process appeared to be reversible. The $\mathrm{pH}$ shifted back towards $\mathrm{pH} 6.9$ (the value set on the $\mathrm{pH}$ titrator) and $\mathrm{O}_{2}$ consumption and $\mathrm{CO}_{2}$ production returned to their former levels, indicating that in a glucose-depleted culture cells metabolize at a basal rate. 


\section{DISCUSSION}

Under $\mathrm{K}^{+}$-limited conditions the steady-state bacterial dry wt is inversely dependent on the growth rate (Mulder et al., 1986). From the same amount of limiting substrate $\left(1 \mathrm{mM}-\mathrm{K}^{+}\right.$under our experimental conditions), at low growth rates more biomass can be formed than at higher growth rates. We showed that the extracellular $\mathrm{K}^{+}$concentration remained very low and constant at all growth rates in the range $0 \cdot 1 \mathrm{~h}^{-1}$ to $0.35 \mathrm{~h}^{-1}$ (Mulder et al., 1986). This implies that the intracellular $\mathrm{K}^{+}$concentration increases with increasing growth rate (Mulder et al., 1986; see also Hueting et al., 1979; Tempest et al., 1966). This is remarkable because thus far it was taken for granted that with increasing growth rate the steady-state concentration of the limiting substrate in the extracellular fluid increases with increasing growth rate (Monod, 1950; Schulze \& Lipe, 1964; Rutgers et al., 1987). Assuming an internal volume of $2.9 \mathrm{ml}$ (g dry wt) ${ }^{-1}$ (Meury \& Kepes, 1981), a bacterial dry wt of $4 \cdot 2 \mathrm{~g} \mathrm{l}^{-1}$ in the stationary phase (Fig. 1) and all $\mathrm{K}^{+}$ to be in the cells, a cytoplasmic $\mathrm{K}^{+}$concentration of $82 \mathrm{mM}$ was calculated. Meury \& Kepes (1981) showed that, in the absence of a carbon source, $\mathrm{K}^{+}$-depleted cells accumulated $\mathrm{K}^{+}$to a level near $100 \mathrm{mM}$. This may lead to the conclusion that under $\mathrm{K}^{+}$-limited conditions it is not the extracellular $\mathrm{K}^{+}$concentration that limits the rate of growth but the cytoplasmic $\mathrm{K}^{+}$ concentration.

We investigated the dependence of bacterial dry wt on the growth rate further in medium-flow stop experiments : $5 \mathrm{~h}$ after stopping the medium flow to the chemostat all cultures approached the same bacterial dry wt, regardless of the steady-state growth rate of the culture at $t=0$. The bacterial dry wt as measured in the stationary phase of a batch culture showed a similar dry wt to the one obtained by extrapolation to $D=0$ in the graph relating dry wt to the dilution rate (Fig. 1). The latter cells were cultured under different conditions. Initially, no substrate was limiting. After some time $\mathrm{K}^{+}$became limiting and finally growth ceased. Fig. 5 shows that cessation of growth and $\mathrm{K}^{+}$limitation are separated in time. Growth did not stop the moment extracellular $\mathrm{K}^{+}$became limiting. From the fact that the extracellular $\mathrm{K}^{+}$concentration remained low $(<0.5 \mu \mathrm{M})$ and the fact that only about $30 \mathrm{~min}$ after this $\mathrm{K}^{+}$concentration had been reached the growth rate of the batch culture slowly declined, it was suggested that $\mathrm{K}^{+}$was redistributed among all the cells before growth ceased. Thus, independently of the previous growth history, the final cell yield on $\mathrm{K}^{+}$in the stationary phase was constant.

Whenever the cultures ran out of glucose, the extracellular $\mathrm{pH}$ of the culture increased towards more alkaline values. At the same time $\mathrm{K}^{+}$was released into the extracellular medium. These findings resemble the observations of Kroll \& Booth (1983) in $\mathrm{K}^{+}$depleted cells. They showed that on $\mathrm{K}^{+}$depletion the $\mathrm{pH}_{\mathrm{in}}$ of cells increased towards the $\mathrm{pH}$ value of the incubation medium. Addition of an energy source led to a controlled acidification of the cytoplasm to $\mathrm{pH}_{\mathrm{in}}=7.6$ (Kroll \& Booth, 1983). According to Booth (1985) the fall in $\mathrm{O}_{2}$ consumption and $\mathrm{CO}_{2}$ production means that the cells have begun to respire endogenous reserves at a low rate. As soon as an energy source is added to the culture again, both $\mathrm{O}_{2}$ consumption and $\mathrm{CO}_{2}$ production return to their former values. Also, $\mathrm{pH}_{\text {out }}$ decreases until the $\mathrm{pH}$ set on the $\mathrm{pH}$ titrator is reached. Our results confirm those of Booth (1985).

We found no significant difference in bacterial dry wt between FRAG 1 (the wild-type) and the mutant FRAG 5 lacking the high-affinity $\mathrm{K}^{+}$uptake system (Mulder et al., 1986). On the other hand, these two strains differ in ATP production rates and in steady-state extracellular $\mathrm{K}^{+}$ concentrations $(<0.5 \mu \mathrm{M}$ for FRAG 1 and about $50 \mu \mathrm{M}$ for FRAG 5) as measured in the chemostat at varying growth rates (Mulder et al., 1986). From our results it appears that for both strains the bacterial dry wt of the cultures in the stationary phase can be found by extrapolation to the dry wt belonging to a culture with a growth rate of near zero, in the plot relating bacterial dry wt to steady-state growth rate (Fig. 1). The mechanism underlying this phenomenon is not known. One might have expected that after stopping the medium flow, no further $\mathrm{K}^{+}$is available for the cells to continue growth, and if all cells retained their $\mathrm{K}^{+}$, growth would stop. However, our model of $\mathrm{K}^{+}$cycling (Mulder et al., 1986) includes a rapid turnover of $\mathrm{K}^{+}$. In this way, all $\mathrm{K}^{+}$remains available to all cells and the cells may easily adapt to their new conditions, if there is still enough glucose present to supply them with energy. That all cultures, independently 
of their former growth history either in the chemostat or in batch culture, finally reach the same bacterial dry wt after stopping the medium flow, suggests that somehow the potassium in the cells can be redistributed over more cells. Growth did not stop immediately after interrupting the medium flow. Considering the steady uptake of glucose and the steady production of $\mathrm{CO}_{2}$ and acetic acid, it seemed as if the cells did not sense that the limiting substrate was no longer added. The cells continued to grow at the same rate for 15-30 min, provided glucose was present. Only after $15-30 \mathrm{~min}$ did the growth rate begin to decline, ultimately to zero. The simplest way to explain all these results is by assuming that growth under $\mathrm{K}^{+}$-limited conditions is limited by the intracellular $\mathrm{K}^{+}$concentration. After interrupting the addition of $\mathrm{K}^{+}$, the growth rate will decline in parallel with the decrease in intracellular $\mathrm{K}^{+}$until the limit of zero growth has been reached.

We are indebted to Dr R. W. Hommes from the laboratory of Microbiology, University of Amsterdam, for valuable discussions. This work was in part supported by the Netherlands Organization for the Advancement of Pure Research (ZWO) under the auspices of the Netherlands Foundation for Chemical Research (SON).

\section{REFERENCES}

Booth, I. R. (1985). Regulation of cytoplasmic pH in bacteria. Microbiological Reviews 49, 359-378.

Durgaryan, S. S. \& Martirosov, S. M. (1978). An electrochemical study of energy dependent potassium accumulation in Escherichia coli: I. Two steps in potassium uptake and osmosensitivity. Bioelectrochemistry and Bioenergetics 5, 554-560.

EPSTEIN, W. (1986). Osmoregulation by potassium transport in Escherichia coli. FEMS Microbiology Reviews 39, 73-78.

Epstein, W. \& Davies, M. (1970). Potassium dependent mutants of Escherichia coli K 12. Journal of Bacteriology 101, 836-843.

EPSTEIN, W. \& LaIMINS, L. (1980). Potassium transport in Escherichia coli: diverse systems with common control by osmotic forces. Trends in Biochemical Science 5, 21-23.

Evans, C. G. T., Herbert, D. \& Tempest, D. W. (1970). The continuous cultivation of micro-organisms. 2. Construction of a chemostat. Methods in Microbiology 2, 277-327.

Herbert, D. (1961). The chemical composition of microorganisms as a function of their environment. Symposia of the Society for General Microbiology 11, 391-416.

Herbert, D., Phipps, P. J. \& Tempest, D. W. (1965). The chemostat: design and instrumentation. Laboratory Practice 14, 1150-1161.

Hueting, S., de Lange, T. \& Tempest, D. W. (1979). Energy requirement for maintenance of the transmembrane potassium gradient in Klebsiella aerogenes NCTC 418: a continuous culture study. Archives of Microbiology 123, 183-188.

Kroll, R. G. \& BoOTH, I. R. (1983). The relationship between intracellular $\mathrm{pH}$, the $\mathrm{pH}$ gradient and potassium transport in Escherichia coli. Biochemical Journal 216, 709-717.

MEURY, J. \& KEPES, A. (1981). The regulation of potassium fluxes for the adjustment and main- tenance of potassium levels in Escherichia coli. European Journal of Biochemistry 119, 165-170.

Meury, J., Robin, A. \& Monnier-Champeix, P. (1985). Turgor controlled $\mathrm{K}^{+}$fluxes and their pathways in Escherichia coli. European Journal of Biochemistry 151, 613-619.

MONOD, J. (1950). La technique de culture continue; theorie et applications. Annales de l'Institut Pasteur 79, 390-410.

Mulder, M. M., Teixeira de Mattos, M. J., Postma, P. W. \& VAN DAM, K. (1986). Energetic consequences of multiple $\mathrm{K}^{+}$uptake systems. Biochimica et biophysica acta 851, 223-228.

Peterson, G. L. (1977). A simplification of the protein assay method of Lowry et al. which is more generally applicable. Analytical Biochemistry 83, 346356.

Rutgers, M., Teixeira de Mattos, M. J., Postma, P. W. \& VAN DAM, K. (1987). Establishment of the steady state in glucose-limited chemostat cultures of Klebsiella aerogenes. Journal of General Microbiology 133, 445-452.

Schulze, K. L. \& LIPE, R. S. (1964). Relationship between substrate concentration, growth rate and respiration rate of Escherichia coli in continuous culture. Archives of Microbiology 48, 1-20.

Tempest, D. W., Hunter, J. R. \& Sykes, J. (1965). Magnesium-limited growth of Aerobacter aerogenes in the chemostat. Journal of General Microbiology 39, 355-366.

TEMPEST, D. W., Dicks, J. W. \& Hunter, J. R. (1966). The interrelationship between potassium, magnesium and phosphorus in potassium-limited chemostat cultures of Aerobacter aerogenes. Journal of General Microbiology 45, 135-146.

Walderhaug, M. O., Dosch, D. C. \& Epstein, W. (1988). Potassium transport in bacteria. In Ion Transport in Bacteria. Edited by B. P. Rose \& S. Silver (in the Press). 